\title{
o Congresso Nacional e as emergências de saúde pública
}

\section{The Brazilian National Congress and public health emergencies}

\author{
Luiz Carlos P. Romero \\ Fundação Oswaldo Cruz. Diretoria Regional de Brasília. Programa \\ de Direito Sanitário. Brasília, DF, Brasil. \\ E-mail: romero.luizcarlosळgmail.com

\section{Maria Célia Delduque} \\ Fundação Oswaldo Cruz. Diretoria Regional de Brasília. Programa \\ de Direito Sanitário. Brasília, DF, Brasil. \\ E-mail: delduque®fiocruz.br
}

\section{Correspondência}

Luiz Carlos P. Romero

Superquadra Norte 209, bloco E, 102, Asa Norte.

Brasília, DF, Brasil. CEP 70854-050.

\section{Resumo}

Analisou-se a resposta do Legislativo Federal Brasileiro frente a quatro emergências de saúde pública recentes, por meio de análise documental de caráter qualiquantitativo, nos bancos de dados de informação legislativa do Congresso Nacional. Observou-se que a resposta se caracterizou por pronunciamentos (de denúncia, de pedidos de providência, de críticas e de elogios à atuação do Poder Executivo) e pela fiscalização dessa atuação por meio de requerimentos de informação, de convocação de autoridades e de audiências públicas. A produção legislativa, no entanto, foi inexpressiva, restrita à aprovação de proposições de suplementação de recursos orçamentários de iniciativa do Poder Executivo. Poucos projetos de lei de iniciativa de parlamentares trataram matérias periféricas ao problema e não prosperaram. Conclui-se que a insuficiência normativa para a atuação das autoridades sanitárias no enfrentamento de emergências de saúde pública não tem sido suprida pelo Poder Legislativo e terá de sê-lo, provavelmente, por iniciativa do Executivo. Palavras-chave: Emergências de Saúde Pública; Legislação Sanitária; Produção Normativa em Saúde; Regulamento Sanitário Internacional; Direito Sanitário. 


\section{Abstract}

The response of the Brazilian Legislative Branch to four recent public health emergencies is analyzed through quali-quantitative documentary held in legislative information databases of the National Congress. It was observed that this response was characterized by public statements (of denunciation, requests for action, criticism and praise to the actions of the Executive Branch) and by the overseeing of these activities through information requests, convening authorities and public hearings. The lawmaking, however, was negligible, restricted to the approval of propositions for supplemental budget resources from the Executive Branch initiative. Few bills of parliamentary initiative approached the problem and were approved. We conclude that the inefficient actuation of health authorities in coping with public health emergencies is caused by the neglect of the Legislative Branch, so the Executive Branch should probably overcome the problem.

Keywords: Public Health Emergencies; Rulemaking on Health; Draft Legislation on Health; International Health Regulations; Health Law.
Ainda que, nos termos da Constituição Federal de 1988, a assistência à saúde seja livre à iniciativa privada, e atividades de recuperação da saúde individual sejam oferecidas tanto por organizações governamentais como por empresas privadas, um conjunto de ações de saúde pública permanece historicamente na esfera de atuação exclusiva da administração pública. O controle de doenças, a vigilância sanitária de alimentos, medicamentos, serviços e outros produtos de interesse para a saúde e a saúde dos portos são exemplos paradigmáticos: apenas organizações estatais implementam ações e mantêm serviços voltados para essas áreas e, como atividades da administração pública, se executam segundo princípios do direito administrativo público.

Isso quer dizer que, em oposição ao princípio que rege o direito privado - ninguém será obrigado a fazer ou deixar de fazer alguma coisa senão em virtude de lei (art. $5^{\circ}$, § II) -, o agente público que executa ações de saúde pública deve pautar sua atuação em obediência ao princípio da legalidade (art. 37), que lhe impõe sujeição à lei em todos os seus procedimentos. Ainda que as normas do direito administrativo confiram à administração prerrogativas sem equivalente nas relações privadas, impõem à sua liberdade de ação sujeições mais estritas do que aquelas a que estão submetidos os particulares. E essas restrições são de natureza legal.

Assim, por exemplo, no âmbito das obrigações do Estado para com a garantia do direito à saúde, está a de não utilizar intervenções médicas compulsórias ou coercitivas, a menos que em situações excepcionais, para tratar doenças mentais ou prevenir e controlar doenças infecciosas. Essas situações excepcionais, no entanto, devem estar sujeitas a condições específicas e restritas, respeitando as boas práticas e os padrões internacionais aplicáveis (UN, 200o).

Entre os padrões internacionais aplicáveis, está o Regulamento Sanitário Internacional (RSI) (Brasil, 2009b), que autoriza as autoridades sanitárias nacionais a adotar, em situações de emergência, como as epidemias, medidas de limitação de direitos individuais - restrição ao trânsito e transporte de pessoas e mercadorias, instituição de quarentena e isolamento, proibição de eventos públicos, obrigação de se submeter compulsoriamente à vacinação e outros procedimentos médicos. 
A autoridade sanitária e o gestor do sistema público de saúde dependem, assim, do legislador, uma vez que, sem o respaldo legal para sua atuação, tornam-se reféns de situações incontroláveis, especialmente quando sua atuação se revela urgente, como na vigência de epidemias. Em razão disso, a ação eficiente do Estado em enfrentar essas condições de saúde coletiva deve poder contar com a produção do aparato legal necessário.

No caso brasileiro, é reconhecido que, apesar da pujante produção normativa posterior à Constituição de 1988, é precário o aparato legal com que contam as autoridades sanitárias, agentes públicos e gestores de saúde para enfrentar emergências de saúde pública causadas por epidemias de doenças infecciosas, mesmo as ações de rotina de controle desses agravos. Ainda que contemos com regulamentação suficiente das atividades de vigilância sanitária e de saúde dos portos, não contamos com normativas que permitam que a atuação das autoridades sanitárias se faça sob o princípio da legalidade frente a emergências representadas por epidemias de doenças infecciosas. Em especial, nossas autoridades sanitárias não contam com suficiente respaldo legal para implementar ações restritivas de direitos e liberdades individuais eventualmente necessárias ao enfrentamento dessas situações.

Reconhecendo que a implementação das disposições do RSI tem implicações para diversas funções e responsabilidades governamentais, exercidas por diversos ministérios e setores, e que é necessário um arcabouço legal adequado para possibilitar e dar respaldo às atividades necessárias, a Organização Mundial da Saúde (OMS) alertou os estados-partes a avaliarem a necessidade de revisar a legislação existente. Em vista disso, mais da metade dos membros do acordo que aprovou o RSI já alterou sua legislação para se adaptar às determinações do regulamento (WHO, 2009). Nosso país, no entanto, ainda não o fez.

Apesar de ratificado por decreto legislativo (Brasil, 2009b), o mais importante objetivo do RSI pode não ser alcançado em nosso país: a ausência de um ordenamento jurídico atualizado pode comprometer a capacidade de nossa saúde pública em responder a novas emergências sanitárias quando e onde elas ocorrerem.
A matéria é apenas parcialmente regulada por uma lei de 1975 - portanto anterior à instituição do atual arcabouço jurídico e institucional que decorreu da Constituição Federal de 1988 - que cuida da notificação compulsória de doenças e da criação do Programa Nacional de Imunização (Brasil, 1975).

A necessidade de incorporação no nosso arcabouço jurídico das medidas de saúde pública preconizadas pelo RSI e para dotar a autoridade sanitária de meios legais para implementá-las já vinha sendo objeto de discussão no país quando a experiência das últimas emergências sanitárias decorrentes das pandemias de síndrome respiratória aguda grave (SARS) e influenza tornou mais evidente a necessidade de uma legislação que, entre outras coisas, substituísse ou emendasse a lei vigente e internalizasse disposições correspondentes do novo regulamento de que o país foi um dos principais propositores e signatário.

Carmo (2007), refletindo sobre a questão, já expressava que

a aplicação do RSI em determinadas situações pode implicar restrições de liberdades individuais, ainda que de forma temporária e justificada com base em evidência científica [...] uma das questões que se coloca é como transitar de forma adequada nesta tênue linha que separa (ou une) a necessidade de proteção da saúde pública coletiva e o respeito às liberdades individuais (p. 62).

Sua conclusão é que, no caso brasileiro, "serão necessárias adequações legislativas [...], não somente visando à implementação do RSI pelo país, como também a fim de que tenhamos instrumentos mais adequados para a preparação e o enfrentamento de emergências de saúde pública" (p. 64). Opinião similar é expressa por Teixeira (2009) quanto à necessidade de o país contar com uma "legislação de emergência".

O relatório da missão que avaliou a resposta brasileira à pandemia de gripe $\mathrm{A}_{\left(\mathrm{H}_{1} \mathrm{~N}_{1}\right)}(\mathrm{PAHO}, 2011)$ registra que o plano brasileiro de preparação faz referência a "avaliar a necessidade de suspender atividades de caráter coletivo" quando o nível de alerta alcançasse a fase 6 (pandemia), mas não indica nenhum procedimento específico. Registra também que nossas autoridades sanitárias cogitaram e che- 
garam a "trabalhar numa lei que permitisse ao setor saúde tomar medidas de distanciamento social”, que não chegou a ser apresentada, por que, segundo elas, não houve necessidade, durante a crise da pandemia de 2009 (p. 42). Um dos problemas detectados pela avaliação é que o país "não conta com uma lei que permita aplicar medidas de saúde pública como a quarentena" (PAHO, 2011, p. vi).

Madeira (2012), em sua monografia sobre as medidas de caráter sanitário adotadas no Brasil para enfrentar a pandemia de gripe $\mathrm{A}\left(\mathrm{H}_{1} \mathrm{~N}_{1}\right)$ e sua potencial ameaça a direitos e liberdades do cidadão, registra a elaboração pelos técnicos do setor, a partir de 2002, de anteprojetos de lei objetivando "atualizar" nossa legislação sanitária, inclusive quanto ao respaldo legal, para que as autoridades sanitárias possam adotar as medidas de saúde pública preconizadas pelo RSI. Também para ela, existem imperativos jurídicos que justificam a revisão de nossa legislação: "seu anacronismo frente à atual conformação do nosso sistema público de saúde e a falta de instrumentos adequados para que o Estado e a sociedade civil consigam organizar-se no enfrentamento dos riscos à saúde pública” (p. 12). Neste último caso, ela está se referindo à insuficiência de provisões normativas que facultem à autoridade sanitária adotar determinadas medidas necessárias ao controle de doenças no que concerne a restrições a indivíduos, a grupos populacionais ou ao ambiente.

Também ela faz referência a alguns anteprojetos de lei elaborados pela equipe técnica do Ministério da Saúde, "visando a necessidade de reformulação e revisão da Legislação Sanitária vigente" (Madeira, 2012, p. 12). O primeiro deles (de 2002) objetivava “dar legitimidade ao Ministério da Saúde para estabelecer estado de quarentena, isolamento compulsório de indivíduos e interdição de ambientes e meios de transportes em situações de emergência epidemiológica" (Madeira, 2012, p. 13). O segundo (de 2006) tipificava "infrações e crimes sanitários" e definia o processo administrativo para sua apuração, em casos de descumprimento de medidas preconizadas pela autoridade sanitária. O terceiro (de 2007) legislava sobre "situações de emergência de saúde pública” (Madeira, 2012, p. 13; Teixeira, 2009).

Nenhum desses anteprojetos chegou a ser encaminhado à apreciação do Congresso Nacional.
Verifica-se que, no âmbito do Poder Executivo, algumas das necessidades de produção normativa do enfrentamento das últimas emergências de saúde pública pela qual o país passou e da atualização da nossa legislação sanitária para controlar doenças chegaram a ser estabelecidas, e até mesmo proposições normativas para supri-las foram elaboradas, sem, no entanto, terem tido o tratamento que lhes permitiria serem transformadas na norma jurídica que o país necessita.

De parte do Poder Legislativo, aquelas emergências sanitárias e necessidades tampouco foram eficientes para gerar a lei que nos falta. A pesquisa objetivou, assim, descrever e explicar o comportamento do Congresso Nacional brasileiro frente a questões de relevante interesse para a saúde, caracterizadas por emergências de saúde pública desencadeadas por epidemias de doenças infecciosas.

Reconhecida a insuficiência do arcabouço jurídico nacional em dotar o Poder Público de bases legais para sua atuação frente a emergências de saúde pública, interessou-se investigar como o Congresso Nacional se comportou nos últimos anos diante de quatro emergências sanitárias relevantes: a sétima pandemia de cólera, nos anos de 1991 a 2005; a pandemia de influenza $\mathrm{H}_{5} \mathrm{~N}_{1}$, que cursou entre 1999 e 2006; a pandemia de SARS, que durou de 2003 a 2005; e a pandemia de influenza $\mathrm{H}_{1} \mathrm{~N}_{1}$, dos anos de 2009 e 2010.

\section{Métodos}

Trata-se de um estudo descritivo e analítico de caráter qualiquantitativo e de base documental, com o emprego de técnica de análise de conteúdo.

Empregamos, para tratar os documentos obtidos, uma técnica de análise de conteúdo - metodologia de base empírica, exploratória quanto ao processo e preditiva ou inferencial quanto ao objetivo, que pode ser definida como aquela que analisa o conteúdo manifesto de um conjunto de documentos por meio da classificação, tabulação e avaliação dos seus temas para determinar seu sentido e efeito provável (Krippendorff, 2004). Segundo Bardin (2004), a técnica visa obter, por procedimentos sistemáticos e objetivos, a explicitação e sistematização do conteúdo de documentos/mensagens por meio da construção de indicadores que permitam a inferência de conhecimentos relativos às condições de produção dessas 
mensagens. Com essa concepção, foram identificados, classificados e quantificados os conteúdos de documentos que tratam de emergências sanitárias e controle de doenças transmissíveis relativos à atuação das duas casas do Congresso Nacional em determinados momentos históricos.

Os tipos de documentos - que correspondem a ações parlamentares - foram quantificados utilizando a proporção (\%) como medida de frequência. A análise e comparação da magnitude dessas frequências permitiram caracterizar a resposta do Poder Legislativo em cada caso e delinear as características desse comportamento.

Quatro emergências sanitárias de elevada magnitude e ocorridas em período recente foram selecionadas, e os contextos político-institucionais em que ocorreram foram caracterizados (Quadro 1) adotando os seguintes critérios de inclusão: (1) a transcendência do evento, isto é, ter constituído risco inusitado e apresentado alto impacto societário (econômico, social, cultural) e propagação (ou risco de) pelo território nacional; (2) o contexto político-institucional em que ocorreram (buscando contemplar diferentes conjunturas tanto do ponto de vista político quanto das instituições de saúde); e (3) a disponibilidade de documentos informatizados e arquivados nos bancos de dados estudados.

A resposta das duas casas do Congresso Nacional a cada uma delas foi caracterizada quanto à natureza (parlamentar, fiscalizadora e legislativa), tempestividade e efetividade. Para tanto, em cada episódio, foram identificados e analisados os pronunciamentos parlamentares quanto a seu escopo; caracterizada a atuação fiscalizadora das duas casas do Congresso Nacional quanto a sua natureza e efetividade e identificada e caracterizada a produção legislativa quanto à espécie normativa e mérito.

Os documentos analisados foram as matérias legislativas em tramitação ou que já tramitaram na Câmara dos Deputados, no Senado Federal e no Congresso Nacional, e os pronunciamentos proferidos por senadores e deputados, presentes em bases de dados gerenciadas e mantidas respectivamente pelo Senado Federal e pela Câmara dos Deputados. Nessas fontes, foram recuperados os textos legislativos - projetos de lei, medidas provisórias, requerimentos e indicações - e os pronunciamentos que trataram do assunto relativo a cada evento. As informações foram coletadas em matrizes específicas para cada assunto (emergência) e espécie de documento (matérias legislativas e pronunciamentos).

A identificação e busca dos documentos foram feitas nos bancos de dados dos sistemas de informação legislativa mantidos pelo Senado Federal (Sicon - Sistema de Informação do Congresso Nacional) e pela Câmara dos Deputados (Sileg - Sistema de Informação Legislativa). Para processar as informações, usamos o programa dos próprios bancos de dados pesquisados, por meio dos quais pode-se recuperar informações usando, como argumento de pesquisa, o assunto, o autor, a origem, as datas, o número da proposição legislativa ou do pronunciamento e/ou quaisquer outras palavras que constassem nos documentos, sendo utilizados individualmente ou combinados. Foram usados como argumento de pesquisa as diferentes denominações com que os agravos foram identificados, e os nomes científicos da doença e de seu agente etiológico, respectivamente a cada emergência/epidemia estudada, foram combinados com o período de duração da epidemia em cada caso.

Quadro I - Emergências sanitárias selecionadas segundo o periodo e o contexto político-institucional em que
ocorreram
\begin{tabular}{|l|l|l|}
\hline Emergência sanitária & Periodo & $\begin{array}{l}\text { Contexto político-institucional } \\
\text { Reforma neoliberal do Estado (Era Collor); recessão econômica; } \\
\text { institucionalização recente do Sistema Único de Saúde (SUS); impedimento } \\
\text { do Presidente da República. }\end{array}$ \\
\hline Pandemia de gripe aviária ( $\left.\mathrm{H}_{5} \mathrm{NI}\right)$ & $1991-2005$ & $\begin{array}{l}\text { Legislatura perdida (escândalos envolvendo o Legislativo); SUS com } \\
\text { problemas de financiamento. }\end{array}$ \\
\hline Pandemia de SARS & $2003-2006$ & $\begin{array}{l}\text { Pleno exercício de funções e prerrogativas do Congresso Nacional; SUS } \\
\text { implantado e funcional. }\end{array}$ \\
\hline Pandemia de gripe suína (HINI) & $2009-2010$ & $\begin{array}{l}\text { Pleno exercício de funções e prerrogativas do Congresso Nacional; vigência } \\
\text { do novo RSI (2005). }\end{array}$ \\
\hline
\end{tabular}


Resultados

\section{A resposta do Congresso Nacional à sétima pan- demia de cólera, no período de janeiro de 1991 a dezembro de 2005}

A pandemia que chegou ao Brasil em 1991 - a sétima - começou no sul da Ásia em 1961, alcançou a África em 1971 e as Américas 20 anos depois. Até sua chegada ao Peru, em janeiro de 1991, já tinha mais de 1.70o.ooo casos em 117 países e estava durando muito mais do que as seis antecedentes (Narkevich et al., 1993).

O reconhecimento de que cursava uma epidemia de cólera no país foi feito pelo Ministério da Saúde em março de 1991. Até 2005, ano do registro dos últimos casos de transmissão autóctone, a epidemia alcançou todas as regiões do país, com 168.598 casos e 2.035 óbitos. O coeficiente de incidência em 1993, ano com o maior número de casos, foi de 39,81/100.00o habitantes, e a letalidade, de 1,11\%. 0 grupo etário mais atingido foi o de maiores de 15 anos, com predomínio no sexo masculino (Brasil, 2014).

A epidemia de cólera encontrou o Brasil em plena reforma neoliberal do Estado (Souza, 2003) e em recessão econômica. O SUS, criado com a Constituição Federal de 1988, dava os primeiros e difíceis passos para se institucionalizar e se estruturar. 0 Congresso Nacional iniciava uma nova legislatura e logo se veria às voltas com a profunda crise institucional criada com o impedimento do presidente da República.

Quando o cólera entrou no Peru, o Congresso Nacional estava em recesso. As primeiras manifestações sobre o assunto, no entanto, só vieram a acontecer 20 dias após o início da primeira sessão legislativa de 1991, tomando vulto a partir de então e concentrando-se nos dois primeiros anos da epidemia. A partir do dia 21 de fevereiro de 1991, um número crescente de discursos passou a ser proferido na Câmara dos Deputados tratando do surto no Peru, fazendo alertas, manifestando preocupação com a entrada e disseminação da doença no país, em especial na Amazônia, e pedindo providências para as autoridades. É daquela primeira semana, também, a apresentação do primeiro projeto de lei sobre a matéria, tratando da informação da popu- lação (Brasil, 1991). Proposição de teor similar foi apresentada em abril de 1992; elas tramitaram apensadas e, apesar de terem tido pareceres favoráveis em duas comissões, acabaram arquivadas ao final da legislatura (Brasil, 1992a).

No Senado, a reação tardou ainda uma quinzena, com um discurso de teor similar aos que vinham sendo proferidos na Câmara dos Deputados e a aprovação de um requerimento de informação ao Ministro da Saúde sobre a penetração do cólera no país, em 7 de março. Naquela sessão legislativa (fevereiro a junho de 1991), foram proferidos 39 discursos sobre o tema na Câmara dos Deputados e 6 no Senado.

Ainda que a epidemia tenha se estendido por quinze anos, a resposta das duas casas do Congresso concentrou-se nos dois primeiros - apesar da crise institucional pela qual passava o país e o parlamento com o processo de impeachment do presidente da República, que durou de maio a dezembro de 1992. Nos anos de 1993 e 1994 - os piores anos do cólera no Brasil, nos quais foi registrada a maior incidência e mortalidade e a doença alcançou todas as regiões do país - foram implementadas apenas 22,6\% das ações parlamentares. Mais de 70\% dos pronunciamentos e a totalidade da atuação fiscalizatória e dos projetos de lei apresentados ocorreram em 1991 e 1992, antes do agravamento do problema e enquanto a doença estava limitada ao Norte e Nordeste - e em plena crise do impeachment do presidente.

A atuação do Congresso Nacional frente à emergência do cólera no país caracterizou-se, assim, pelo grande predomínio de pronunciamentos, poucas ações fiscalizatórias e pequena produção normativa (Tabela 1). A fiscalização de políticas e ações govermanentais caracterizou-se pelo encaminhamento de requerimentos de informação ao Ministro da Saúde nos primeiros anos da epidemia. O Ministro da Saúde foi convidado e compareceu ao Plenário do Senado em dois momentos (abril e maio de 1992) para prestar esclarecimentos sobre a situação. A produção normativa limitou-se à Câmara dos Deputados pela proposição de três projetos de lei: dois, já citados, tratando de instituir ações de comunicação social para esclarecer a população sobre a doença; e um estabelecendo gratuidade nos transportes públicos para os agentes de saúde, atuando no combate ao cólera (Brasil, 1992b). Nenhum deles prosperou. 
A análise dos pronunciamentos no período evidenciou uma atividade parlamentar prolífera, pelo menos nos primeiros momentos da epidemia, caracterizada pela preponderância de alertas, denúncias e manifestações de preocupação com o risco de entrada e alastramento da epidemia no país (ou seu agravamento), acompanhadas ou não de pedidos de providência às autoridades. Denúncias ou críticas à situação de despreparo do SUS para enfrentar a epidemia e a precariedade das ações e serviços públicos de saúde foram matéria de seis pronunciamentos, e as consequências econômicas da epidemia (em decorrência da queda no consumo de hortigranjeiros e da redução da entrada de turistas no país), de outros três (Tabela 2).

\section{A resposta do Congresso Nacional ao risco de pandemia de influenza $\mathrm{H}_{5} \mathrm{~N}_{1}$ durante os anos de 1999 a 2006}

Nos últimos anos, têm sido crescentes as oportunidades de exposição de pessoas ao vírus aviário da influenza, e sua transmissão para humanos vem se dando em níveis sem precedentes nos tempos modernos. Ainda que sejam desconhecidas as exatas condições que levam à emergência de pandemias de influenza, os especialistas advertem que novas pandemias da doença, de origem natural, ocorrerão inevitavelmente - ainda que não se possa prever com exatidão quando -, causando números substanciais de doentes, mortes, convulsão social e pânico generalizado (Dowdle, 2006; Gensheimer et al., 2003).

Em 1999, a OMS, reconhecendo o aumento do risco da ocorrência de uma nova pandemia, recomendou providências a serem tomadas pelos governos e divulgou a primeira versão das Recomendações de preparação para pandemia de Influenza (WHO, 1999). No final de 2003, uma epidemia de influenza aviária, causada por uma cepa altamente patogênica do subtipo $\mathrm{H}_{5} \mathrm{~N}_{1}$, teve lugar no Vietnã, estendendo-se, nos anos seguintes, para outros países da Ásia, apesar dos esforços para limitar seu progresso, pelo abate de grandes quantidades de aves de criação. A doença não se limitou às aves e, já em janeiro de 2004, autoridades sanitárias vietnamitas notificaram um surto de doença respiratória grave em humanos (Thorson et al., 2006). A partir de então, foram notificados casos humanos da doença em nove outros países: Azerbaijão, Camboja, China, Djibuti, Egito, Indonésia, Iraque, Tailândia, Turquia. Até dezembro de 2006, já tinham sido notificados 263 casos humanos da gripe aviária, com 158 óbitos (WHO, 2007).

No Congresso Nacional, o período em que o país se preparou para a epidemia de gripe aviária caracterizou-se por um contexto institucional de baixíssima produtividade legislativa por razões conjunturais - a "legislatura perdida" (Nascimento, 2007). Nos dois anos finais da $52^{\mathrm{a}}$ legislatura, uma série de escândalos praticamente paralisou a atividade legislativa da Câmara dos Deputados. Levantamento publicado pelo jornal Correio Braziliense mostra que, desde 1989, quando o Regimento Interno da Câmara dos Deputados foi aprovado, nunca tinham sido arquivados tantos projetos de lei por não terem sido apreciados como no final daquela legislatura. Enquanto deputados usavam os dias de sessões para se defender de acusações, preparar relatórios de cassação e negociar absolvições, milhares de projetos se acumulavam à espera de tramitação (Nascimento, 2007).

A resposta do Congresso Nacional ao risco de entrada da epidemia de gripe aviária no Brasil também foi caracterizada pela dominância de pronunciamentos (6o\% do total de ações) e praticamente ausência de ações legislativas (Tabela 1). A mobilização do Parlamento diante do risco de uma pandemia de gripe iniciou-se timidamente na Câmara dos Deputados, em 1999, e assim se manteve até 2003, intensificando-se em 2004 com a piora da situação na Ásia. Os anos de agravamento da crise político-institucional foram, paradoxalmente, aqueles em que os parlamentares mais se mobilizaram com o problema: $80 \%$ das ações - inclusive 3 de 4 projetos de lei - se concentraram nos anos de 2005 e 2006.

As primeiras ações realizadas foram indicações ao Ministério da Saúde para ampliar a vacinação antigripal da população. A elas se seguiram requerimentos de informação e de convocação do ministro da saúde para prestar esclarecimentos quanto à preparação do país para enfrentar a possível pandemia e, mais tardiamente, o requerimento de audiências públicas. Com o agravamento da epidemia na Ásia, obrigando grandes abates de aves de criação, os 


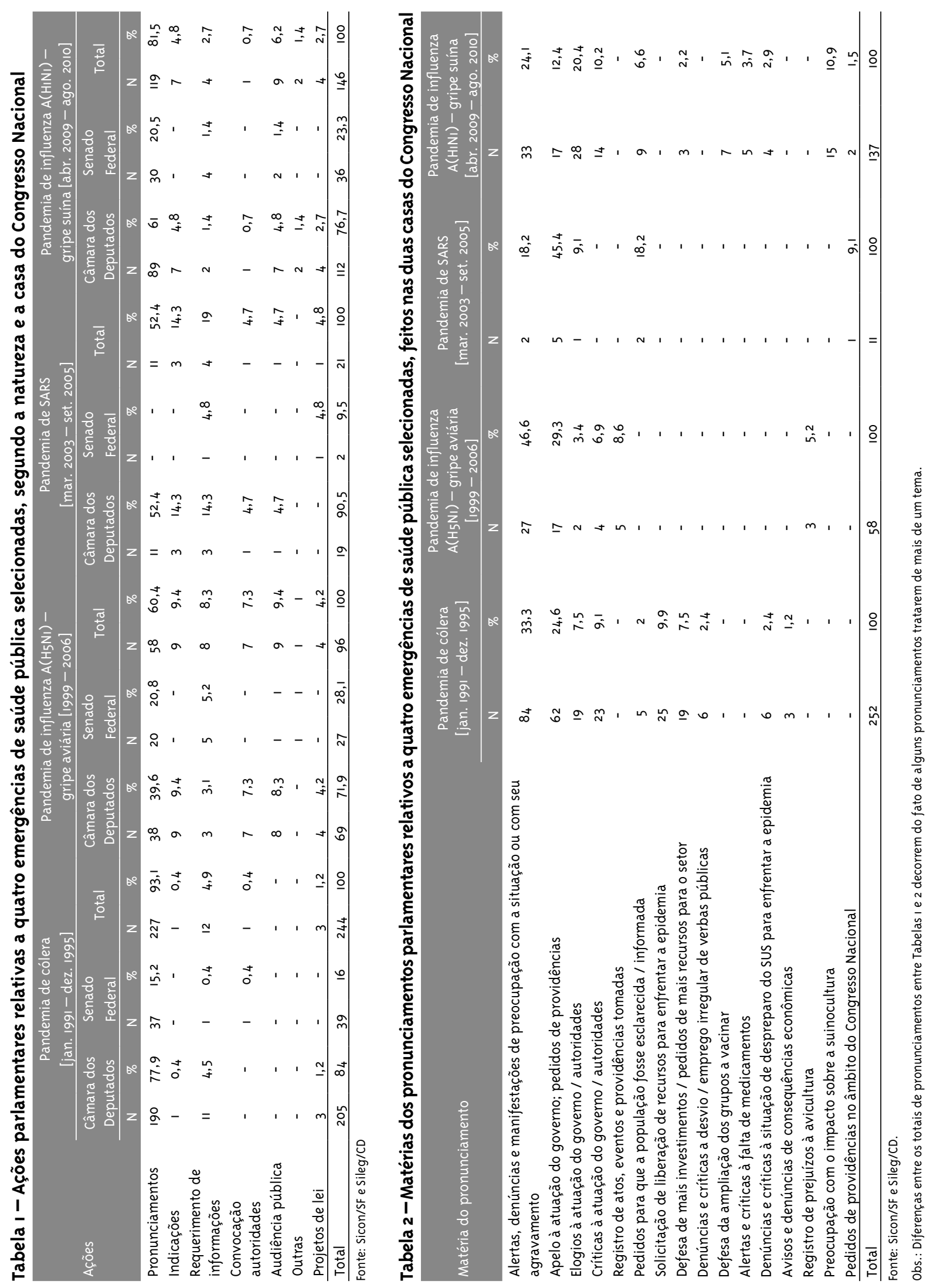


requerimentos de informação e as convocações para as audiências passaram a ser - também e principalmente - dirigidos a autoridades das áreas de agricultura e defesa.

A temática dos pronunciamentos concentrou-se no alerta para o problema, na denúncia do despreparo do país para enfrentá-lo e no pedido de providências ao governo e autoridades (três quartas partes dos pronunciamentos tratavam de pelo menos um dos temas citados). A preocupação dos parlamentares era, inicialmente, com o risco para a saúde humana e, posteriormente, com os riscos para a sustentabilidade das atividades econômicas, em especial a agroindústria avícola (Tabela 2).

Dos quatro projetos apreciados no período, três tratavam de suplementações orçamentárias para os ministérios da Defesa e da Agricultura e foram de iniciativa do Poder Executivo. O quarto cuidava de instituir uma campanha nacional de vacinação contra a gripe que não chegou a tramitar por conter vício de iniciativa (isto é, compete privativamente ao presidente da República - e não ao Congresso - a iniciativa de dispor sobre a organização e o funcionamento da administração federal) (Brasil, 1999).

\section{A resposta do Congresso Nacional à pandemia de SARS (março de 2003 a maio de 2005)}

O súbito e letal aparecimento da SARS foi o mais dramático episódio das últimas décadas relativo à emergência de novas doenças desconhecidas (WHO, 2003).

No dia 12 de março de 2003, a OMS lançou um alerta sobre o aparecimento de uma doença respiratória grave, de causa indeterminada, que estava se propagando rapidamente entre funcionários de hospitais de Hong Kong e do Vietnã. Logo ficou evidente que a doença estava também se espalhando internacionalmente por meio de importantes rotas de transporte aéreo, uma vez que hospitais de Cingapura e Toronto, no Canadá, reportaram casos similares.

Os primeiros casos conhecidos da nova doença ocorreram na província chinesa de Guangdong em novembro de 2002, mas só se tornou conhecido pela OMS em março de 2003 (Bradseher, 2003). A partir de então, ocorreram surtos da doença em Hong Kong, no Canadá, na Alemanha, em Taiwan, no Vietnã, em Cingapura, na Tailândia, na Malásia, nas Filipinas, nos Estados Unidos e na África do Sul. Casos importados foram registrados na Austrália, na Nova Zelândia, na Coréia do Sul, na Inglaterra, na Irlanda, na Suécia, na França, na Suíça, na Itália, na Espanha, na Rússia, na Romênia, na Índia, na Indonésia, no Kuwait e na Mongólia.

Assim como veio, a epidemia se foi, graças ao esforço coordenado das autoridades sanitárias dos países afetados e da OMS. Foram reconhecidos três surtos: o maior e mais grave cursou com caráter pandêmico entre novembro de 2002 e junho de 2003, causando mais de oito mil casos e cerca de oitocentos óbitos; o segundo, de dezembro de 2003 a janeiro de 2004, causado por uma forma menos virulenta do vírus e responsável por apenas quatro casos; e nove outros casos decorrentes de acidentes de laboratório na China, Taiwan e Singapura, entre março e maio de 2005 (Yardley, 2005).

Segundo a OMS, ocorreram, no total, 8.096 casos e 774 óbitos da doença, em 29 países. Apesar do relativo pequeno número de pessoas afetadas e mortas, a epidemia de SARS "causou mais medo e comoção social do que qualquer outra doença, nos tempos atuais" e "puxou, como nunca antes, o cinto das economias, aleijou o comércio e as viagens internacionais e esvaziou as ruas de algumas das mais prósperas cidades do mundo" (WHO, 2006, p. 7). A epidemia causou perdas econômicas da ordem de 59 bilhões de dólares no mundo todo e, na China, reduziu em $1,3 \%$ o produto interno bruto e gerou perdas de 17,9 bilhões de dólares.

Não ocorreram casos na América do Sul. No entanto, casos suspeitos foram notificados na Colômbia e no Brasil. O primeiro caso suspeito de SARS no Brasil foi notificado em São Paulo, em 2 de abril de 2003 (País..., 2003), e o segundo ocorreu sete dias depois (Brasil..., 2003). No total, enquanto durou a epidemia, 28 casos foram notificados como suspeitos em nosso país. Todos, afinal, não confirmados.

0 país conseguiu passar pela pandemia sem ter tido casos da doença. No entanto, ela representou um risco sanitário potencial relevante e chegou a ter impacto econômico significativo. Mesmo sem casos no Brasil, a epidemia trouxe prejuízos à economia nacional, em decorrência da suspensão de missões oficiais e comerciais dirigidas à China e ao sudeste asiático, 
da redução das exportações brasileiras para a região (Comércio..., 2003) e da produtividade de indústrias que dependiam de insumos importados, em especial de países asiáticos e do transporte aéreo. Em vista do inusitado e da gravidade da situação, ela teve grande cobertura da imprensa nacional e internacional.

Diferentemente das anteriores, a epidemia de SARS encontrou o Congresso Nacional em pleno exercício de suas funções e prerrogativas e sem intercorrências à sua atuação. A mobilização do parlamento brasileiro se fez logo nos primeiros momentos: quinze dias após o alerta da OMS $\left(1^{\circ} \mathrm{de}\right.$ abril de 2003), a Câmara dos Deputados aprovou requerimento de informação ao Ministro da Saúde sobre medidas de prevenção que se pretendia tomar. Com exceção de dois pronunciamentos feitos em julho e setembro, todas as demais ações se concentraram num período de sessenta dias - em média, uma ação a cada três dias.

Essa atuação deu-se preponderantemente pela Câmara dos Deputados e, predominantemente, por pronunciamentos - mais da metade das ações realizadas. A competência fiscalizadora se concentrou na Câmara dos Deputados e se fez, principalmente, por meio de requerimentos de informações (Tabela 1).

Os pronunciamentos constituíram, assim, as principais ações dos parlamentares em relação à pandemia e estiveram voltados principalmente para indicar ou pedir atuação das autoridades sanitárias, inclusive que a população fosse informada e esclarecida sobre o problema, e para manifestações de preocupação com o desenrolar dos fatos (Tabela 2).

$\mathrm{Na}$ área legislativa, apenas um projeto de lei foi apresentado ao Senado Federal, obrigando as companhias de transporte aéreo, ferroviário e rodoviário de passageiros a disponibilizarem máscaras cirúrgicas descartáveis a seus passageiros (Brasil, 2003). A proposição foi rejeitada pela Comissão de Assuntos Sociais daquela Casa (para a qual tinha sido distribuída para apreciação em decisão terminativa) depois de sete anos de tramitação e acabou arquivada.

\section{A resposta do Congresso Nacional à influenza pandêmica de 2009-2010}

Em 24 de abril de 2009, o Ministério da Saúde do México tornou pública a ocorrência de uma epidemia de doença respiratória na área metropolitana da Cidade do México, suspendeu as aulas em todos os estabelecimentos de ensino, fechou museus e estabelecimentos similares e recomendou à população evitar lugares concorridos e eventos de massa (Lacey; McNeil Junior, 2009). Nesse mesmo dia, a OMS confirmou a existência do surto da "gripe suína $\mathrm{A}\left(\mathrm{H}_{1} \mathrm{~N}_{1}\right)$ " no México, com a ocorrência de 854 óbitos, além de casos humanos nos estados da Califórnia e Texas, dos Estados Unidos, e que o novo vírus tinha sido isolado e identificado num laboratório de referência da organização no Canadá (WHO, 2013). Nos dias seguintes foram notificados casos nos Estados Unidos, Canadá, Espanha e Escócia, e casos suspeitos apareceram no Brasil, Austrália, Israel e Nova Zelândia.

Em 29 de abril, a OMS elevou o nível de alerta, recomendando que todos os países ativassem imediatamente seus planos de preparação para enfrentar aquela emergência e, em 11 de junho, em vista da evidência da transmissão sustentada do novo vírus em mais de um continente, declarou a pandemia. O novo vírus foi denominado "vírus da influenza pandêmica $\mathrm{A}\left(\mathrm{H}_{1} \mathrm{~N}_{1}\right)$ 2009" (WHO, 2013).

Em nove semanas após a detecção do vírus no México, tinham sido notificados casos da nova gripe em todos os continentes (PAHO, 2009). No período de cinco meses, o vírus tinha se espalhado por todo o mundo, tendo sido confirmados laboratorialmente mais de 340 mil casos e notificados mais de 4.100 óbitos (WHO, 2011). Segundo a OMS, até o final do ano de 2009, tinham sido registrados casos em 194 países. A região mais afetada foi a das Américas, onde ocorreram $67 \%$ dos óbitos (Brasil, 2009f). Uma revisão de 27 estudos de soroprevalência realizados em 19 países estimou, em 2013, que a pandemia de 2009-2010 infectou $24 \%$ da população mundial $47 \%$ dos acometidos na faixa de 5 a 19 anos -, causando 18.500 óbitos, com uma letalidade de o,02\% (Van Kerkhove et al., 2013).

No Brasil, nossas autoridades sanitárias deram andamento ao plano de enfrentamento, iniciando a fase de contenção, que se estendeu até 15 de julho, quando foi reconhecida a transmissão sustentada do vírus em nosso meio, passando então para a fase de mitigação, que se manteve até agosto de 2010, quando a OMS declarou a pandemia finalizada (PAHO, 2011). 
Os primeiros casos confirmados no país aconteceram em 7 de maio de 2009. 0 maior número de casos e óbitos ocorreu nos meses de julho e agosto, enquanto se observava a aparição de sucessivas ondas da epidemia nas diferentes regiões do país. Ao final de 2009 - quando a epidemia arrefeceu, com o número de casos reduzido quase a zero -, as cifras oficiais eram de 48.978 casos confirmados de síndrome respiratória aguda grave e 2.051 óbitos (Brasil, 2009f). Uma segunda onda manifestou-se em fevereiro de 2010, afetando especialmente a região Norte, com elevada mortalidade de gestantes, evidenciando também problemas de acesso a serviços assistenciais na região.

Durante o desenrolar da epidemia, foram registrados casos em todas as regiões do país, mas as mais afetadas foram a Sul e a Sudeste. No país como um todo, a taxa de incidência foi de 14,5 casos por 100 mil habitantes, alcançando 66,2 no Sul e 9,7 no Sudeste. A taxa de mortalidade no país como um todo foi de 1,1 por 100 mil habitantes. No entanto, nos estados da região Sul, chegou a 3 óbitos por 100 mil habitantes, uma das taxas mais elevadas de toda a região das Américas (PAHO, 2011).

Quando a pandemia de gripe $\mathrm{A}\left(\mathrm{H}_{1} \mathrm{~N}_{1}\right)$ foi reconhecida como uma emergência de saúde pública de importância internacional e, posteriormente, chegou ao Brasil, o Congresso Nacional estava em pleno exercício de suas funções e prerrogativas, sem crises políticas ou institucionais no horizonte. O SUS estava implantado e atuante, tendo como principal problema o equacionamento das questões relativas ao seu financiamento, paralisado no Congresso há nove anos. 0 país tinha sido signatário e um dos principais articuladores da elaboração e aprovação do novo RSI, aprovado pela Assembleia da OMS de maio de 2005. O novo regulamento encontrava-se em vigor há dois anos (15 de julho de 2007) e tinha sido internalizado em nosso ordenamento jurídico por meio do Decreto Legislativo n ${ }^{0}$ 395, de 2009. Um plano de preparação para emergências de saúde pública já existia desde 2003, frente ao risco da ocorrência de uma pandemia causada pelo vírus da gripe aviária, e foi prontamente acionado.

A primeira manifestação do Congresso Nacional sobre a pandemia aconteceu no Plenário do Senado Federal em 27 de abril de 2009, com um pronuncia- mento no qual seu autor relatava a preocupação dos governos em todo o mundo com o combate à gripe suína e conclamava a Subcomissão de Saúde da Casa a debater a questão. Naquela semana, foram feitos três outros discursos sobre o tema no Senado e doze na Câmara dos Deputados, e apresentados dois requerimentos para a realização de audiências públicas nas comissões de Seguridade Social e Família; Agricultura, Pecuária e Abastecimento; Defesa do Consumidor e Relações Exteriores, da Câmara.

A análise temporal das ações de deputados e senadores diante da pandemia evidencia que elas se concentraram em dois períodos: nos primeiros 30 dias após a declaração da emergência sanitária de importância internacional (abril e maio de 2009) e nos dois meses de maior incidência de casos no país (agosto e setembro de 2009). Nesses dois períodos, foram feitos cerca de $80 \%$ dos pronunciamentos, apresentados a quase totalidade dos requerimentos e três dos quatro projetos de lei sobre a matéria.

Também nesse episódio, a atuação do Congresso Nacional caracterizou-se pela intensa atividade parlamentar - mais de 80\% do total de ações foram pronunciamentos - e por importante atividade fiscalizadora - com a aprovação de requerimentos de informações e de convocação do ministro da saúde, pela realização de audiências públicas conjuntas das comissões de Saúde, Agricultura, Defesa do Consumidor e Relações Exteriores, tanto na Câmara como no Senado, e pela realização de uma comissão geral no Plenário da Câmara dos Deputados (Tabela 1). A composição de uma comissão especial para acompanhar e fiscalizar os procedimentos do governo em relação à gripe $\mathrm{H}_{1} \mathrm{~N}_{1}$ foi aprovada - no mês de agosto, no pico da epidemia -, mas a comissão não chegou a ser constituída.

Mais de uma centena de discursos foram proferidos nas duas casas do Congresso. A análise de seus conteúdos mostrou que os temas mais frequentes desses pronunciamentos foram manifestações de preocupação com a situação ou com o agravamento da epidemia (um de quatro discursos tratava desse tema), a preocupação com o impacto sobre a suinocultura nacional (um décimo deles cuidava disso) e apelos à atuação do governo (outro décimo). Cerca de um terço dos pronunciamentos tratavam da atuação do Poder Executivo, para elogiá-la ou criticá-la (Tabela 2). 
A produção normativa caracterizou-se pela conversão em lei de duas medidas provisórias - de iniciativa do Poder Executivo, portanto - abrindo créditos extraordinários para financiar atividades de enfrentamento da pandemia (Brasil, 20oga; 2009e $)^{1}$ e pela apresentação de dois projetos de lei ordinária à Câmara dos Deputados, que tratavam de matérias diferentes: o primeiro estabelecia regras emergenciais específicas para combater epidemias ou pandemias no âmbito nacional (Brasil, 2009c), e o segundo instituía concessão de licença para afastar trabalhadoras grávidas dos setores público e privado pelo prazo de 30 dias (Brasil, 2oogd).

As regras emergenciais que o citado projeto estabelecia eram de duas naturezas. No primeiro grupo, estava a autorização para o Poder Executivo declarar estado de emergência de saúde em casos de epidemias reconhecidas pela OMS e, em decorrência disso, controlar e restringir a circulação de pessoas e requisitar serviços hospitalares, laboratoriais e outras instalações de serviços públicos e privados que fossem necessárias, por período determinado. No segundo grupo está a instituição de tratamento tributário diferenciado pelo prazo de doze meses para aquisição, fabricação e importação de bens necessários no mercado interno e no exterior. Trata-se da única iniciativa parlamentar visando dotar nossas autoridades sanitárias de instrumentos legais para enfrentar emergências de saúde pública.

Nenhum desses projetos prosperou, não tendo sido apreciados sequer na primeira das comissões designadas, razão pela qual foram arquivados ao final da legislatura.

Em síntese, a resposta do Parlamento Federal às emergências sanitárias teve características similares em todas as situações estudadas: foi concentrada nos momentos iniciais e de maior gravidade e, do ponto de vista da produção normativa, insatisfatória. Em todos os casos, o Parlamento reagiu, inicialmente, com a produção de pronunciamentos nos quais os parlamentares manifestavam preocupação quanto à situação e pediam providências e, a seguir, passou a fiscalizar as ações implementadas pelas autoridades sanitárias por meio de requerimentos de informação, convocação de autoridades e audiências públicas.

A produção legislativa de iniciativa parlamentar foi quase nula em todos os casos, limitando-se a aprovar proposições sobre matéria orçamentária de iniciativa do Executivo e a propor projetos de lei tratando de questões periféricas ao problema, que, de qualquer forma, não prosperaram. Em apenas um dos episódios estudados chegou a ser apresentado projeto de lei para atribuir competência aos agentes públicos de saúde para implementar algumas ações de limitação de direitos individuais, voltadas para conter e mitigar epidemias. Essa proposição, no entanto, foi rejeitada e arquivada.

O que se observou foi que o Congresso Nacional reagiu com uma postura mais política do que propositiva, e, do ponto de vista da produção legislativa, sua atuação foi insuficiente e dissociada das necessidades de enfrentar novas condições epidemiológicas.

Como explicar essa incapacidade ou recusa do Congresso Nacional em produzir a normatização de que o país necessita e demanda reiteradamente, a cada nova emergência de saúde pública?

Poder-se-ia considerar que a urgência e a flexibilidade com que é demandada a decisão política necessária ao enfrentamento dessas emergências não são compatíveis com os padrões, os ritos e os processos lógico-formais do processo legislativo. Essa, no entanto, não deve ser sequer parte da explicação, uma vez que, mesmo passada a emergência e diante da recorrência de eventos similares, as casas legislativas do Congresso Nacional não se mobilizaram para produzir normas necessárias. Não se cuida, aqui, portanto, de um modelo de exercício de poder ou de elaboração normativa que escape

\footnotetext{
1 Medida Provisória n ${ }^{0}$ 463, de 22 de maio de 2009, que abre crédito extraordinário em favor de diversos órgãos do Poder Executivo (que inclui um crédito de R\$ 102.400.ooo,oo em favor do Fundo Nacional de Saúde e da Agência Nacional de Vigilância Sanitária para, "tendo em vista a situação emergencial relativa à saúde pública de importância internacional, conforme estabelecido pela OMS, [...] a execução de despesas imprescindíveis para o desenvolvimento de ações do Governo para a prevenção, preparação e combate a uma possível pandemia de influenza"); e Medida Provisória n 469, de 5 de outubro de 2009, que abre crédito extraordinário de R\$ 2.168.172.00o,oo "para execução de despesas imprescindíveis ao desenvolvimento de ações emergenciais dos Ministérios da Saúde e dos Transportes para prevenção, preparação e combate à pandemia”.
} 
à lógica do processo legislativo habitual - bem ao contrário.

Da mesma forma, a densidade técnica do tema não pode ser alegada como razão para essa não atuação, na medida em que os parlamentos contemporâneos, diante da complexidade técnica e jurídica das matérias que são levadas a sua apreciação cotidiana, não prescindem de consultorias legislativas muito bem preparadas, capazes de aportar os elementos técnicos necessários à produção legislativa. A apresentação de projeto de lei de iniciativa parlamentar - ainda que limitado à regulamentação de apenas alguns aspectos da questão - durante um dos episódios estudados serve de evidência para suficientes condições de proposições legislativas sobre a matéria pelas casas do nosso Congresso.

Em decorrência, as necessidades de emendar ou substituir nossa legislação para dotar as autoridades sanitárias e demais agentes públicos dos instrumentos jurídicos de que necessitam para enfrentar problemas como os estudados não têm sido supridas pelo Parlamento, mesmo frente à reiteração de situações de extrema gravidade epidemiológica. 0 Parlamento brasileiro tem, nos últimos 20 anos, tratado politicamente esse tema, reconhecendo-o como relevante, analisando e elaborando politicamente as pretensões normativas do ambiente social e sanitário trazidas pela emergência de reiteradas crises sanitárias, sem, no entanto, produzir as leis necessárias. 0 desencadeamento do processo legislativo não se faz oportunamente no âmbito das Casas do Congresso Nacional, seja nesses contextos de crise, seja após sua superação, seja na sua reincidência.

Verifica-se, no entanto, que algumas das necessidades de atualizar nossa legislação sanitária para enfrentar emergências de saúde pública e controlar doenças - em especial diante das últimas emergências de saúde pública pelas quais o país passou: as pandemias de SARS e de influenza $\mathrm{A}\left(\mathrm{H}_{1} \mathrm{~N}_{1}\right)$ - chegaram a ser estabelecidas, e até mesmo proposições normativas foram elaboradas para supri-las, sem, no entanto, terem o encaminhamento devido.

Da mesma forma que no Congresso Nacional, no âmbito do Poder Executivo, o tratamento político da questão concentrou-se na análise e elaboração política das pretensões normativas trazidas pela emergência de reiteradas crises sanitárias, mas avançou pouco na seleção de alternativas viáveis e não alcançou a fase de tomada de decisão.

\section{Conclusão}

A insuficiência do nosso arcabouço jurídico diante da necessidade de atuação de nossas autoridades sanitárias para enfrentar emergências de saúde pública - na qualidade de agentes públicos que têm de pautar seus procedimentos pelo princípio da legalidade - não está sendo suprida pelo Congresso Nacional, mesmo com as reiteradas emergências e re-emergências de doenças transmissíveis evidenciadas nos últimos 20 anos, todas com importante impacto societário.

Frente àquelas emergências de saúde pública, o Parlamento reagiu, em todos os casos, como caixa de ressonância das percepções e perplexidades sociais em relação ao problema, com pronunciamentos nos quais os parlamentares faziam alertas, manifestavam preocupação quanto à situação, pediam providências e debatiam questões pertinentes ao enfrentamento das crises (o aporte de recursos, a atuação das autoridades sanitárias, os impactos econômicos, a informação da população etc.). Além disso, fiscalizou as ações implementadas pelas autoridades sanitárias com a utilização dos meios de que dispunha: requerimentos de informação, convocação de autoridades e realização de audiências públicas.

As diferentes conjunturas políticas e institucionais em que as epidemias estudadas encontraram o Congresso Nacional levam a considerar que a resposta similar em todos os casos reflete mais a existência de um padrão e menos a conjuntura, isto é, que ela reflete mais o tratamento político possível do que uma reação a determinado contexto político-institucional.

Esse comportamento evidencia o tratamento político dado àqueles problemas pelas nossas casas legislativas federais. Sua resposta, no entanto, é quase nula em relação à produção legislativa de iniciativa parlamentar, restringindo-se a aprovar proposições de suplementação orçamentária de iniciativa do Executivo e a propor projetos de lei tratando de questões periféricas ao problema e que, mesmo assim, não prosperam. 
O estudo da resposta do Congresso Nacional frente a quatro emergências sanitárias importantes ocorridas nos últimos 20 anos - pandemias de cólera (1991-2005), gripe aviária (1999-2006), SARS (20032005) e gripe suína (2009-2010) - permite evidenciar que dificilmente se iniciará no Congresso Nacional a revisão de nossa Lei de Vigilância Epidemiológica ou a proposição de uma nova norma mais adequada - ao que determina o RSI vigente - para regular a atuação do Poder Público em matéria de controle de doenças.

Para chegar a esse resultado, o Poder Executivo terá, muito provavelmente, participação decisiva, tanto na elaboração do ato normativo e na iniciativa de sua proposição ao Congresso Nacional quanto no acompanhamento e emulação do processo legislativo, para obter apreciação e aprovação oportunas.

\section{REFERÊNCIAS}

BARDIN, L. Análise de conteúdo. Lisboa:

Edições 70, 2004.

BRADSEHER, K. Hong Kong: alert on mysterious virus. The New York Times, New York, p. 9, 14 mar. 2003.

BRASIL. Casa Civil. Lei no 6.259, de 30 de outubro de 1975. Dispõe sobre a organização das ações de Vigilância Epidemiológica, sobre o Programa Nacional de Imunizações, estabelece normas relativas à notificação compulsória de doenças, e dá outras providências. Subchefia para Assuntos Jurídicos. Disponível em: <http://www.planalto. gov.br/ccivil_o3/leis/L6259.htm>. Acesso em: 15 fev. 2017.

BRASIL. Câmara dos Deputados. Projeto de Lei $n^{\circ} 828$, de 25 de maio de 1991. Institui Campanha Nacional de orientação à população sobre a cólera. Disponível em: <http://bit.ly/2lLFnug>. Acesso em: 16 fev. 2017.

BRASIL. Câmara dos Deputados. Projeto de Lei $n^{\circ}$ 2.652, de 9 de abril de 1992. Obriga os meios de comunicação de massa a veicularem matérias oficiais de prevenção e combate à cólera. 1992a. Disponível em: <http://bit.ly/2lGh4NQ>. Acesso em: 16 fev. 2017.

BRASIL. Câmara dos Deputados. Projeto de Lei $n^{\circ}$ 2.999, de 2 de julho de 1992. Dispõe sobre o direito à gratuidade nos transportes interestaduais para os agentes de saúde. 1992b. Disponível em: <http://bit.ly/2lLM3IO>. Acesso em: 16 fev. 2017.

BRASIL. Câmara dos Deputados. Projeto de Lei $n^{\circ}$ 976, de 18 de maio de 1999. Institui campanha de vacinação anual contra a gripe, por intermédio do Ministério da Saúde. Disponível em: <http://bit. ly/2l8NnCo>. Acesso em: 16 fev. 2017.

BRASIL. Ministério da Saúde. Secretaria de Vigilância em Saúde. Cólera: aspectos epidemiológicos. Brasília, DF, 2014. Disponível em: <http://bit.ly/2nnfJsH>. Acesso em: 31 jan. 2013.

BRASIL. Senado Federal. Projeto de Lei $n^{\circ} 147$, de 24 de março de 2003. Obriga as companhias de transporte aéreo, ferroviário e rodoviário de passageiros a disponibilizar máscaras cirúrgicas descartáveis a seus passageiros. 2003. Disponível em: <http://bit.ly/2lGiUOW>. Acesso em: 16 fev. 2017.

BRASIL. Senado Federal. Medida Provisória $n^{\circ} 463$, de 22 de maio de 2009. Abre crédito extraordinário, em favor de diversos órgãos do Poder Executivo, no valor global de R\$ 1.217.677.730,oo (um bilhão, duzentos e dezessete milhões, seiscentos e sete mil, setecentos e trinta reais), para os fins que especifica. 20o9a. Disponível em: <http://bit. ly/2mBzJvu>. Acesso em: 16 fev. 2017.

BRASIL. Assembleia Mundial de Saúde. Decreto Legislativo $\mathrm{n}^{0}$ 395, de 9 de julho de 2009. Aprova o texto revisado do Regulamento Sanitário Internacional, acordado na Organização Mundial da Saúde, em 23 de maio de 2005. Diário Oficial da União, Brasília, DF, 1o jul. 20ogb. Disponível em: <http://bit.ly/2mxyAVe>. Acesso em: 15 fev. 2017.

BRASIL. Câmara dos Deputados. Projeto de Lei $n^{0}$ 5.781, de 12 de agosto de 20o9. Estabelece regras emergenciais e específicas para combate a epidemias ou pandemias no âmbito nacional, inclusive tratamento tributário diferenciado para aquisição, fabricação e importação de bens necessários no mercado interno e no exterior. 2009c. Disponível em: <http://bit.ly/2naMKIZ〉. Acesso em: 16 fev. 2017. 
BRASIL. Câmara dos Deputados. Projeto de Lei $n^{\circ}$ 5.789, de 13 de agosto de 2009. Concede licença às trabalhadoras grávidas do setor público e privado pelo período de 30 dias. 2oogd. Disponível em: <http://bit.ly/2n202Ii $>$. Acesso em: 16 fev. 2017 .

BRASIL. Câmara dos Deputados. Medida Provisória $n^{\circ} 469$, de 5 de outubro de 20o9. Abre crédito extraordinário, em favor dos Ministérios da Saúde e dos Transportes, no valor global de $\mathrm{R}$ 2.168.172.0oo,oo, para os fins que especifica. 2ooge. Disponível em: <http://bit.ly/2n2qoLN>. Acesso em: 16 fev. 2017.

BRASIL. Ministério da Saúde. Secretaria de Vigilância em Saúde. Informe Epidemiológico Influenza Pandêmica (H1N1) 20o9, Brasília, DF, v. 1, n. 11, 2009f.

BRASIL espera resultados para saber se tem Sars. O Estado de São Paulo, São Paulo, p. 35122, 21 abr. 2003. Disponível em: <http://bit.ly/2nHNSXq>. Acesso em: 20 mar. 2017.

CARMO, E. H. Regulamento Sanitário Internacional, emergências de saúde pública, liberdades individuais e soberania. Revista de Direito Sanitário, São Paulo, v. 8, n. 1, p. 61-64, 2007. COMÉRCIO entre Brasil e China é afetado pela Sars. Notícias Terra, [s. l.], $1^{0}$ maio 2003. Disponível em: <http://bit.ly/2ojySR3>. Acesso em: 20 mar. 2017.

DOWDLE, W. R. Influenza pandemic periodicity, virus recycling and the art of risk assessment. Emerging Infectious Diseases, Atlanta, v. 12, n. 1, p. 34-39, 2006.

GENSHEIMER, K. F. et al. Influenza pandemic preparedness. Emerging Infectious Diseases, Atlanta, v. 9, n. 12, p. 1645-1648, 2003.

KRIPPENDORFF, K. Content analysis: an introduction to its methodology. Thousand Oaks: Sage Publications, 2004.

LACEY, M.; MCNEIL JUNIOR, D. G. Fighting deadly flu, Mexico shuts schools. The New York Times, New York, p. A4, 25 abr. 2009.
MADEIRA, A. Pandemia de influenza $A\left(H_{1} N_{1}\right)$, medidas sanitárias e os direitos e liberdades individuais e coletivas: o caso do Brasil. 2012. 62 p. Monografia (Especialização em Direito Sanitário) - Fundação Oswaldo Cruz, Brasília, DF, 2012.

NARKEVICH, M. I. et al. The seventh pandemic of cholera in the USSR, 1961-89. Bulletin of the World Health Organization, Geneva, v. 71, n. 2, p. 189-196, 1993.

NASCIMENTO, S. A legislatura perdida. Correio Braziliense, Brasília, DF, p. 2-3, 6 mar. 2007.

PAHO - PAN AMERICAN HEALTH ORGANIZATION. Response to pandemic $\left(H_{1} N_{1}\right)$ 2009 in the Americas: lessons and challenges. Miami, 2009. Disponível em: <http://bit. ly/2n23vGL >. Acesso em: 15 fev. 2017.

PAHO - PAN AMERICAN HEALTH ORGANIZATION. Caracterización de la respuesta de Brasil a la pandemia de Influenza $H_{1} N_{1}$ 2009: reporte de misión. [s. l.], 2011. 14 p. Disponível em: <http://bit.ly/2n24R4D> Acesso em: 28 jan. 2013.

PAÍS tem $1^{\text {a }}$ suspeita de pneumonia asiática. Folha de São Paulo, São Paulo, p. C1, 3 abr. 2003. Disponível em: <http://bit.ly/2mTAnoH>. Acesso em: 15 fev. 2017.

SOUZA, J. Críticas à construção de um Estado neoliberal no Brasil (1987-2002): 15 anos de profundas mudanças. In: CONGRESO INTERNACIONAL DEL CLAD SOBRE REFORMA DEL ESTADO Y DE LA ADMINISTRACIÓN PUBLICA, 8., 2003, Panamá. Anais... Panamá: Centro Latinoamericano de Administración para el Desarrollo, 2003.

TEIXEIRA, M. G. et al. Vigilância em saúde: é necessária uma legislação de emergência? Revista de Direito Sanitário, São Paulo, v. 10, n. 2, p. 126-144, 2009.

THORSON, A. et al. Is exposure to sick or dead poultry associated with flulike illness? A population-based study from a rural area in Vietnam with outbreaks of highly pathogenic avian influenza. Archives of International Medicine, Budapeste, v. 166, n. 1, p. 119-123, 2006. 
UN - UNITED NATIONS. CESCR General comment $n^{\circ} 14$ : the right to the highest attainable standard of health. Geneva, 20oo. Disponível em: <http:// bit.ly/10G8Cmj>. Acesso em: 15 fev. 2017.

VAN KERKHOVE, M. D. et al. Estimating age-specific cumulative incidence for the 2009 influenza pandemic: a meta-analysis of a $\mathrm{A}_{(}\left(\mathrm{H}_{1} \mathrm{~N}_{1}\right)$ pdmo9 serological studies from 19 countries. Influenza and Others Respiratory Viruses, Oxford, 2013. Disponível em: <http://bit.ly/2lAIXbC >. Acesso em: 15 fev. 2017.

WHO - WORLD HEALTH ORGANIZATION. Influenza pandemic plan. The role of $\mathrm{WHO}$ and guidelines for national and regional planning. Geneva, 1999. Disponível em: <http://bit. ly/2naKL70>. Acesso em: 15 fev. 2017.

WHO - WORLD HEALTH ORGANIZATION. SARS: lessons from a new disease. Genebra, 2003. Disponível em: <http://bit.ly/2lAEVjb>. Acesso em: 15 fev. 2017.

WHO - WORLD HEALTH ORGANIZATION. Western Pacific Region. SARS: how a global epidemic was stopped. Geneva: WHO, 2006.
WHO - WORLD HEALTH ORGANIZATION. WHO activities in avian influenza and pandemic influenza preparedness: January - December 2006. Geneva, 2007. Disponível em: <http://bit. ly/2lZ5wmv>. Acesso em: 15 fev. 2017.

WHO - WORLD HEALTH ORGANIZATION. Epidemiological summary of pandemic influenza $\mathrm{A}\left(\mathrm{H}_{1} \mathrm{~N}_{1}\right) 2009$ virus - Ontario, Canada, June 2009. Weekly Epidemiological Record, Geneva, v. 84,

n. 47, p. 485-491, 2009.

WHO - WORLD HEALTH ORGANIZATION. Implementation of the International Health Regulations (2005). Geneva, 2011. Disponível em: <http://bit.ly/1DUvxHK>. Acesso em: 30 abr. 2013. WHO - WORLD HEALTH ORGANIZATION. Evolution of a pandemic $A\left(H_{1} N_{1}\right)$ 20o9: April 2009 - August 2010. Geneva, 2013. Disponível em: <http://bit.ly/2naMAkW>. Acesso em: 15 fev. 2017.

YARDLEY, J. After its epidemic arrival, SARS vanishes. The New York Times, New York, 12 maio 2005. Disponível em: <http://nyti.ms/2lAYesP>. Acesso em: 15 fev. 2017.

\section{Contribuição dos autores}

Romero responsabilizou-se pela coleta dos dados, sua sistematização, análise e redação do artigo. Delduque responsabilizou-se pela revisão dos dados e redação do artigo.

Recebido: 09/11/2015

Aprovado: $13 / 01 / 2016$ 